Original scientific paper

\title{
INFLUENCE OF DRUM CUTTING HEIGHT ON SHEARER CUTTING UNIT VIBRATION BY CO-SIMULATION METHOD
}

\author{
Sun, L. Q. ; Jiang, K. ; Zeng, Q. L. ${ }^{* * *}$; Gao, K. D. "\# \& Zhang, X. D.* \\ *College of Mechanical and Electronic Engineering, Shandong University of Science and Technology, \\ Qingdao, 266590, China \\ ${ }^{* *}$ College of Information Science and Engineering, Shandong Normal University, Jinan, 250358, \\ China \\ E-Mail: gaokuidong22@163.com $\left({ }^{\#}\right.$ Corresponding author $)$
}

\begin{abstract}
The shearer consists of the cutting department for coal cutting, the transmission system for power transmission and the hydraulic system for height adjustment. The cutting department determines the service life and work efficiency of the mining machine in application. To study the vibration of the cutting department when the drum works at different heights, the hydromechatronical co-simulation model of the cutting department of the mining machine was established. Using the simulation model and input signal, the vibration of the motor gear, sun gear, and cutting unit arm was simulated when the shearer drum worked at different heights, and the cause of the vibration was analysed in detail in the study. Simulation results demonstrate that a more evident vibration occurs at the measurement positions on the ranging arm when the piston moves by $0.44 \mathrm{~m}$. Moreover, the hydraulic cylinder, sun gear and motor gear also easily suffer vibrations with different levels and more attention should be paid on those components during shearer design process.

(Received in October 2020, accepted in February 2021. This paper was with the authors 2 months for 2 revisions.)
\end{abstract}

Key Words: Shearer, Cutting Department, Vibration Analysis, Hydromechatronical Co-Simulation Method, Coal Cutting

\section{INTRODUCTION}

As the key equipment in longwall mining, the shearer determines the efficiency of coal production by its performance and capability. In cutting condition, the loads of cutters are severe and complicated $[1,2]$. The cutting unit is the main working component of the shearer and directly bears the loads of coal cutting [3]. Hence, the cutting property research and the vibration research of the shearer cutting unit play a very important role in the improvement of shearer capability.

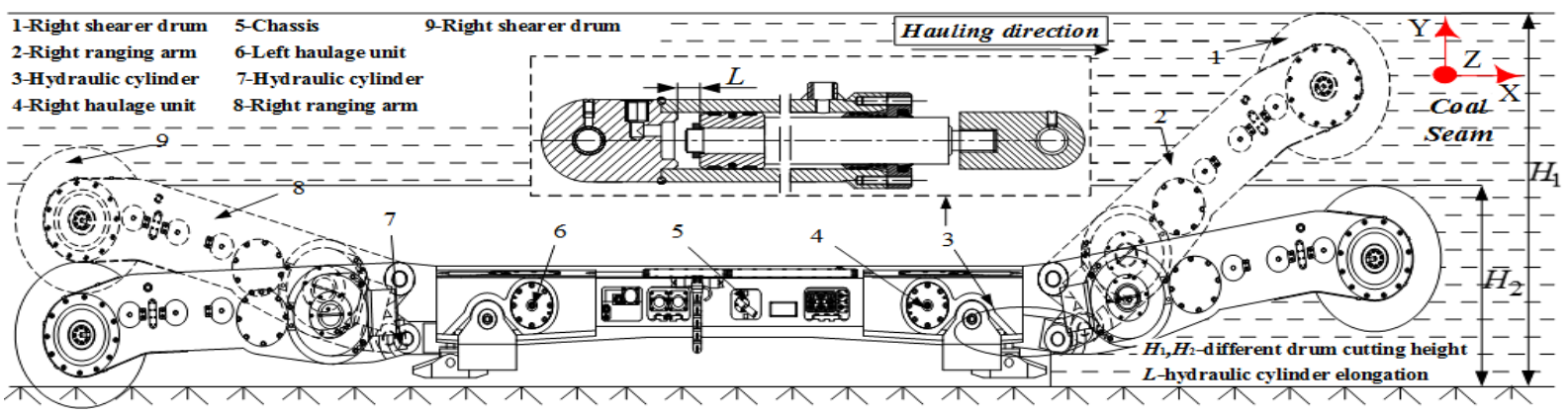

Figure 1: Structure of the shearer.

Fig. 1 shows the structure of a shearer. The drum height is determined by the piston position of hydraulic cylinder. When the drum is positioned at different heights, the torques and forces caused by the drum cutting forces on the pin that connects the range arm and the haulage unit differ. In addition, the different forces delivered to the hydraulic cylinder cause discrepancy of piston movement for the coupling effect of the forces and oil pressure in the cylinder. 


\section{STATE OF THE ART}

The cutting properties can be obtained by physical testing and numerical modelling. Gao et al. [4] made orthogonal test in the coal cutting bed with model drums and model picks. Results showed that the cutting torque is greatly influenced by coal compressive strength and cutting depth. Che et al. [5] explained the interaction between rock and of polycrystalline diamond compact (PFC) cutters with linear cutting tests. Liu et al. [6] made coal cutting experiments to study the cutting force under different impact angles, head face radii of pick body and cutting depths. As for numerical modelling method, in the past, various numerical modelling method have been widely used. Akhshik and Rajabi [7] simulated the cuttings transport in underbalanced drilling with Discrete elements method (DEM) and the method proved to be available for transportation simulation. Moon and Oh [8] presented a multi-indentation simulation using DEM analysis to study the relationship between the interaction of the s/p ratio and intact rock properties. Apart from DEM analysis, the finite element method (FEM) analysis is also used in numerical analysis. Cruz et al. [9] made post-fracture analyses with finite element method. Blecich et al. [10] simulated the heat and mass transfer process with finite element method. The FEM analysis is widely adopted in the mining fields, particularly. Menezes et al. [11] studied the relationship between cutting parameters and cutter performance with finite element method. Wan et al. [12] compared the cutting forces on cutters in the finite element method when coal cutting happened by single cutter and shearer drum. In these numerical modelling methods, the FEM is more mature than the others and has been widely adopted. The loads on the drum close to real situation can be obtained with the help of FEM drum cutting simulation.

The cutting unit of shearer which consists of ranging arm, drum and hydraulic cylinder is a typical mechanical-hydraulic coupling system. In ranging arm, there is a complex gear transmission system which deliver the power from electric motor to drum. Hydraulic cylinder is used to adjust the drum height. During shearer working, gear transmission and hydraulic cylinder will perform excessive vibration, which affect the stability and reliability. Some researches on shearer hydraulic system, electrical system and electromechanical system have been performed, and the reliability and maintenance of these systems also have been analysed. Chen et al. [13] established the non-linear dynamic model of shearer and with the model, the dynamic reliability of gear is available for prediction. Sheng et al. [14] firstly established the electromechanically model for the rotor system under electromagnetic excitation. Hoseinie et al. [15] sought to learn about the reliability of the shearer and a basic methodology was applied in his research for the shearer reliability study. Hoseinie et al. [16] conducted a reliability analysis on the subsystem of shearer machine and found that big changes in world price of raw coal greatly influenced maintenance costs of the cutting arms. Yang et al. [17] established the vibration model of cutting part of shearer to study the dynamic response of the cutting part under sine excitation. Wang et al. [18] proposed a new continuous variable transmission system which can regulate speed and the cutting motor and the performance such as the speed ratio, efficiency and torque ratio were also studied. Moreover, the co-simulation method was widely used in recent research, which proved the feasibility to integrate different software together and also improved the accuracy of the simulation results. Liu et al. [19] conducted an electromechanical model of the driving system of the shearer to simulate electromechanical dynamic characteristics. Barbagallo et al. [20] made co-simulation and the co-simulation model allowed a complete view of the dynamic behaviour for design and set-up. Meng et al. [21] adopted the co-simulation technology to study the automatic attitude adjustment behaviour of support. Ren et al. [22] constructed an ADAMS-EDEM coupling analysis model to study the dynamic performance of heavy scraper conveyors. Although some coupling research method should be recommended, the coupling relation among drum loads, cutting unit drive system vibration and hydraulic system pressure shock has never been discussed. 
Hence, to get the dynamic responses of shearer and the its components during coal cutting process, the co-simulation, which consists of drum cutting model, transmission system and hydraulic system, is essential. With drum cutting model, the cutting force and torque on shearer drum during cutting process are available. Then, set the cutting force and torque as the signal input into the transmission system model and the vibration of the components in transmission system model, such as sun gear and motor gear, can be obtained. Moreover, the dynamic performance of hydraulic cylinder, especially the dynamic characteristics of piston in cylinder can be found with the hydraulic system model in this paper. The outcome in this paper conveniences the model design and qualitative analysis of ranging arm, motor and sun gear during shearer design process.

The reminder of this study is organized as follows. Section 3 introduces the drum cutting model, transmission system model and hydraulic system model used in this paper. Section 4 makes some analysis on the dynamic responses of ranging arm, sun gear, motor gear when shearer drum works at different heights. It also investigates the pressure in the rear and rod end cylinder under different drum working heights. Section 5 summarizes the conclusions.

\section{METHODOLOGY}

The models and methods used in this work are consistent with those in our previous study $[23,24]$, namely, the model of the shearer drum cutting the coal, the transmission system model of the shearer cutting unit, the hydraulic system model of height adjustment, and the hydromechatronical co-simulation model of the shearer cutting unit. Fig. 2 shows hydromechatronical co-simulation model and data transmission in those models.

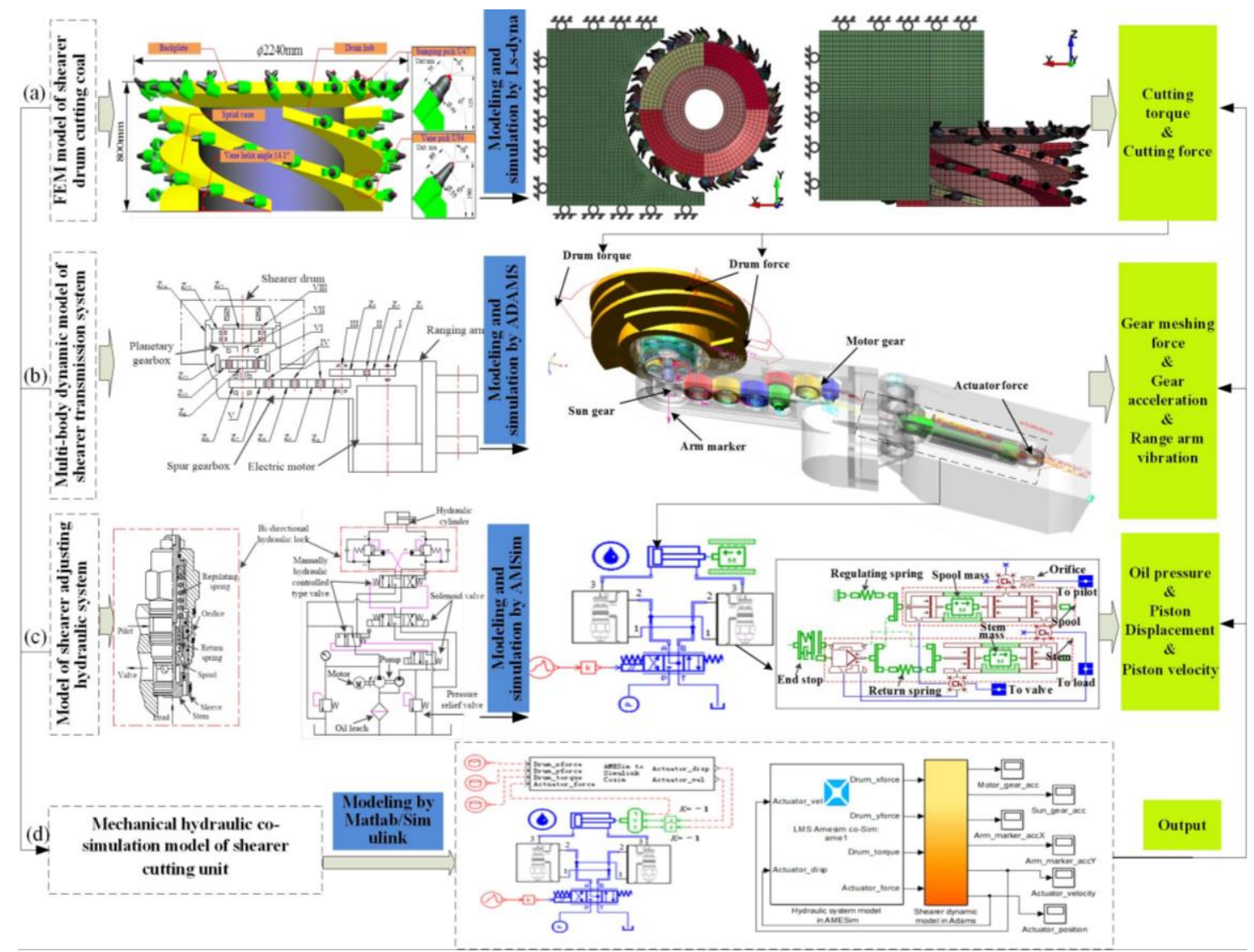

Figure 2: Hydromechatronics co-simulation model.

In the drum cutting model, FEM software LS_Dyna was applied. The material model and interaction between drum and coal was of vital important for the results [25]. The material 
model in this paper is consistent with our previous research and the shearer drum is still simulated with rigid material [23]. For the shearer drum, the mass density is $7.85 \mathrm{t} / \mathrm{m}^{3}$, Young's modulus is $2 \times 10^{5} \mathrm{MPa}$, and Poisson's ratio is 0.3 . For the coal seam, the mass density is 1.30 $\mathrm{t} / \mathrm{m}^{3}$, Young's modulus is $3100 \mathrm{MPa}$, Poisson's ratio is 0.3 , the ultimate tensile strength (UTS) is $1.2 \mathrm{MPa}$, and shear strength is $9 \mathrm{MPa}$.

In the transmission system, the transmission system of the shearer cutting unit was composed of electric motor, spur gearbox, planetary gearbox, and range arm. A multibody dynamic model of the shearer cutting unit can also be constructed with the help of ADAMS. The parameters used in the transmission are consistent with our previous research [23].

In the hydraulic system, the hydraulic system of height adjustment includes one electric motor, one double gear pump, one oil leach, one hydraulic cylinder, one bidirectional hydraulic lock, one manually hydraulic controlled type value, two solenoid values, and two pressure relief values. The hydraulic system was constructed with AMESim to evaluate the dynamic response of hydraulic cylinder. In this research, the different drum cutting heights $(2.607 \mathrm{~m}, 3.428 \mathrm{~m}$ and $4.311 \mathrm{~m})$ were given by controlling the extrusions of the hydraulic cylinder piston $(0.24 \mathrm{~m}, 0.44$ $\mathrm{m}$ and $0.64 \mathrm{~m}$ ). The other parameters related with hydraulic components are consistent with our precious research [23].

In addition, MATLAB software was used in this paper and the hydromechatronic model of those three models were implemented. From Fig. 2, the cutting torques and forces were obtained from the simulation of the coal cutting model. The multibody dynamic mechanical model of the shearer was exported from ADAMS using A/Control plug tool, and the model was compiled into an S-function in MATLAB. The hydraulic system model was also compiled into an Sfunction using the AMESimCosim interface.

\section{RESULTS AND DISCUSSIONS}

\subsection{Drum cutting force and torque}

To study the dynamic response of the ranging arm in the working process, the load applied on the ranging arm is vital and should be consistent with that in actual conditions. According to previous dynamic response research of shearer ranging arm, the load applied on the ranging arm is usually replaced with step signal, impulse signal, or random signal. However, the load caused by drum cutting in actual situations is neither step signal nor impulse signal, particularly not the simple combination of the mentioned signals. Therefore, the dynamic response of the ranging arm obtained under simple signals or their combinations is the approximate result.

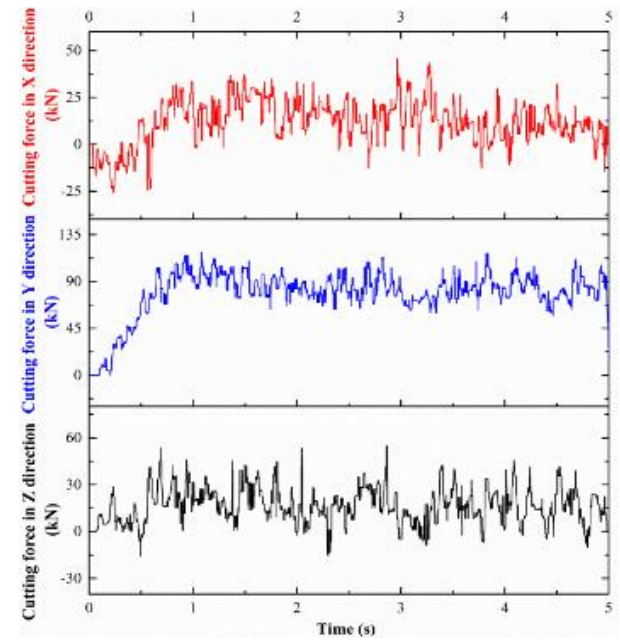

a) Drum cutting forces

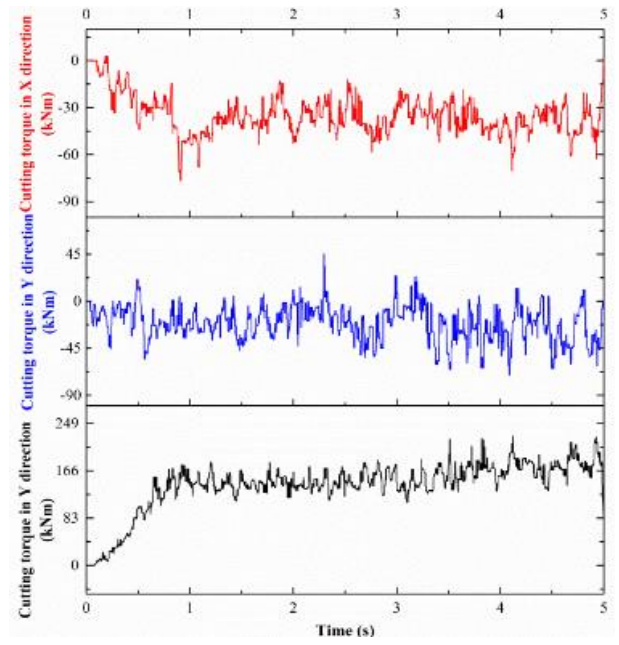

b) Drum cutting torques

Figure 3: Drum cutting forces and torques. 


\subsection{Dynamic responses of the motor gear}

According to the previous contents, drum height was determined by the extrusion of the hydraulic cylinder piston. Different drum heights can also be expressed by various extrusions of the hydraulic cylinder piston. Fig. 4 shows the meshing force and acceleration of the motor gear at different extrusions of the piston.

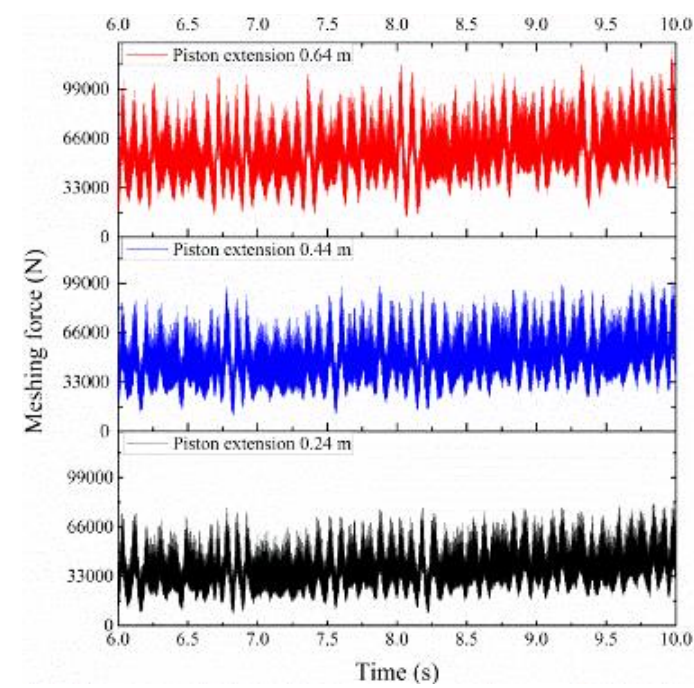

a) Motor gear meshing forces

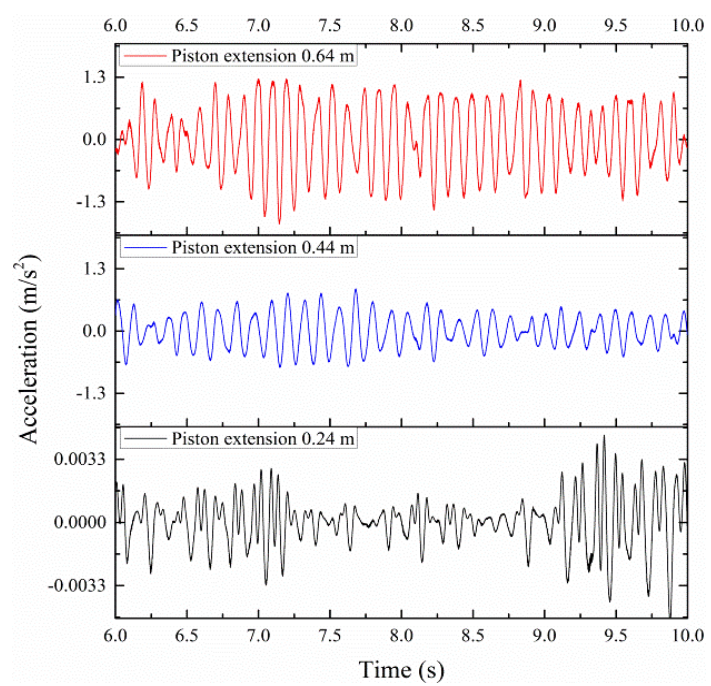

b) Motor gear accelerations

Figure 4: Meshing forces and accelerations of motor gear at different extrusions of the hydraulic cylinder piston.

Fig. 4 a shows that the minimum of the meshing force of motor gear varies slightly when the piston is at different extrusions, and the minimum meshing force is approximately $22000 \mathrm{~N}$. By contrast, the maximum of the meshing force is vulnerable to extrusions of the piston. Fig. $4 \mathrm{a}$ shows that when extrusions of the piston move from $0.64 \mathrm{~m}$ to $0.24 \mathrm{~m}$, the maximum meshing force of the motor gear decreases and mainly varies from $11000 \mathrm{~N}$ to $6600 \mathrm{~N}$. Fig. 4 b shows that the acceleration of the motor gear can also be affected by the extrusions of the piston. When the piston extrusion is at $0.64 \mathrm{~m}$, the mean peak value of the acceleration is approximately $1.2 \mathrm{~m} / \mathrm{s}^{2}$. When the shearer drum height falls and the piston extrusion is at $0.24 \mathrm{~m}$, the mean peak value of the acceleration mainly varies from $1.2 \mathrm{~m} / \mathrm{s}^{2}$ to $0.003 \mathrm{~m} / \mathrm{s}^{2}$, which is a decrease of $99.75 \%$. Thus, the working height of the shearer drum has a remarkable effect on the acceleration of the motor gear.

\subsection{Dynamic responses of the measured point on range arm}

The intersection between the rear side of the ranging arm and the axis of the shearer drum is selected for the vibration measurement of the ranging arm to study the vibration characteristics of the ranging arm. Finally, the displacement and acceleration on this measurement points are available when the drum works at different heights, as shown in Fig. 5.

Fig. 5 a shows that the accelerations of the point on the ranging arm slightly differ when the piston is at different positions. When the piston moves by $0.44 \mathrm{~m}$, a more evident vibration occurs at the measurement positions on the ranging arm. The differences in vibration are no more than $30 \%$ of the largest vibration when the piston is at different positions. Fig. $5 \mathrm{~b}$ shows that the vibration amplitude is relatively large and beyond $0.2 \mathrm{~m}$ sometimes. Therefore, the vibration on the ranging arm is evident under the influence of cutting load on the shearer drum. In turn, the vibration of the ranging arm leads to further vibration on the shearer drum and influences the cutting load on the shearer drum. However, the vibration of the ranging arm cannot be fed back to the shearer drum using the method in this study, and it might lead to 
several deviations between the results obtained in this part and those from real working conditions. However, the conclusions, which prove the existence of evident, violent vibration in the coal cutting process, are still useful for shearer design. In addition, Fig. 5 b shows that the difference of the displacement of the ranging arm is no more than $35 \%$ under different piston positions. Thus, the displacement and acceleration of the ranging arm can be influenced by drum cutting positions, but those influences on the ranging arm are not as apparent as those on the motor gear.

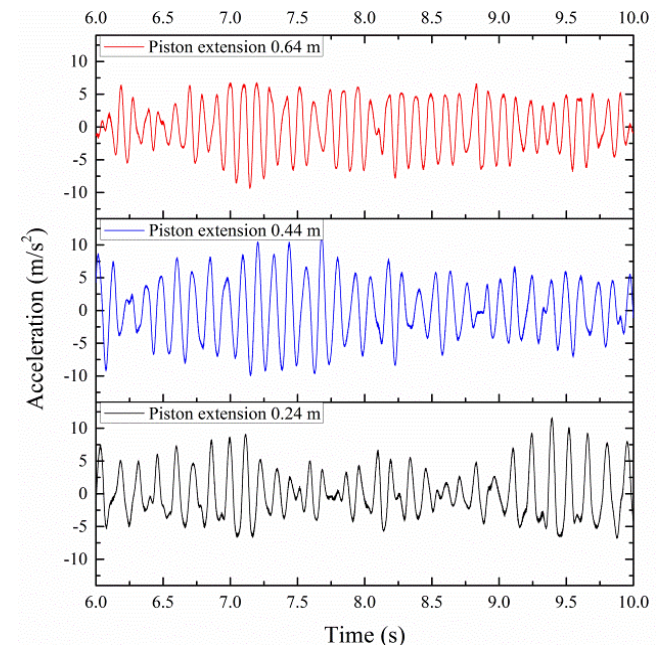

a) Accelerations of the point on ranging arm

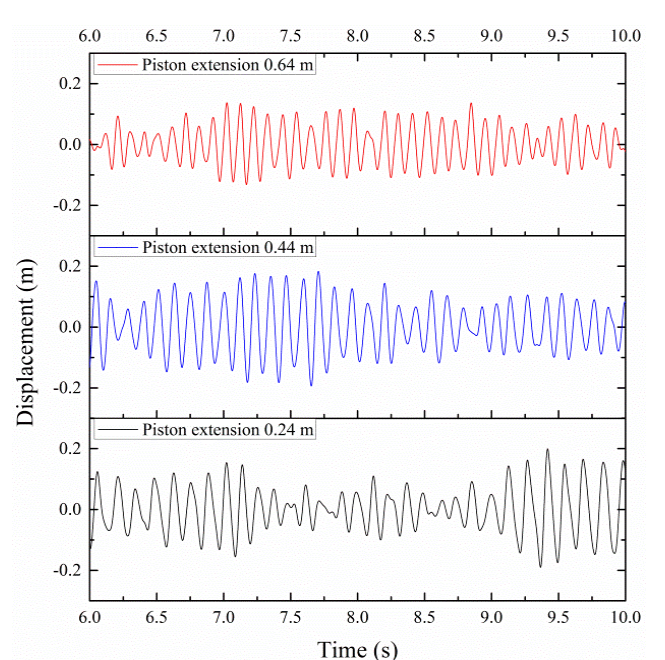

b) Displacements of the point on ranging arm

Figure 5: Accelerations and displacements of the point on ranging arm at different extrusions of the hydraulic cylinder piston.

\subsection{Dynamic responses of the sun gear}

Fig. 6 shows the sun gear meshing force and acceleration under different piston extrusions. Fig. 6 a shows that the differences in the sun gear meshing force are not apparent when the shearer drum works at different heights. Fig. $6 \mathrm{~b}$ shows that the sun gear acceleration varies greatly under different piston extrusions. When the working height of the shearer drum falls, the acceleration amplitude fluctuations of sun gear mainly decreases from $11.9 \mathrm{~m} / \mathrm{s}^{2}$ to $1.2 \mathrm{~m} / \mathrm{s}^{2}$, which is a decrease of approximately $85 \%$. Thus, the working height of the shearer drum is an important consideration in the variation of sun gear acceleration.

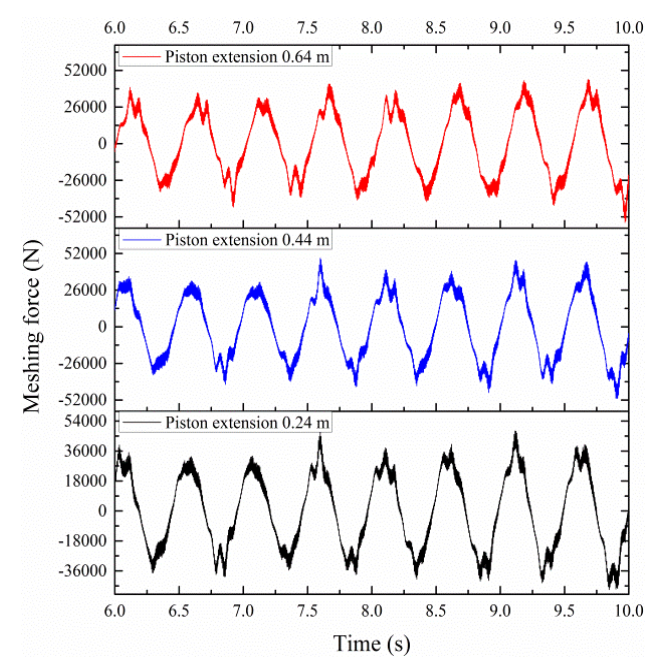

a) Sun gear meshing forces

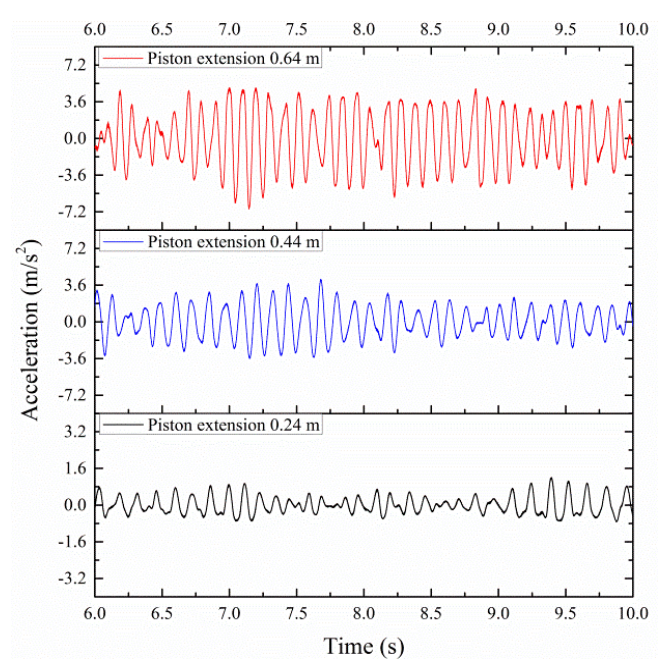

b) Sun gear accelerations

Figure 6: Meshing forces and accelerations of Sun gear at different extrusions of the hydraulic cylinder piston. 


\subsection{Dynamic responses of the hydraulic cylinder}

As a vital actuator for the height adjustment of the shearer drum, the hydraulic cylinder must be strong enough to withstand the impact. Thus, the response of the hydraulic cylinder under different cutting heights of the shearer drum determines whether the shearer drum operates reliably. The displacement and acceleration of the hydraulic cylinder piston are studied and discussed as the main dynamic response, as shown in Figs. $7 \mathrm{a}$ and $7 \mathrm{~b}$, respectively.

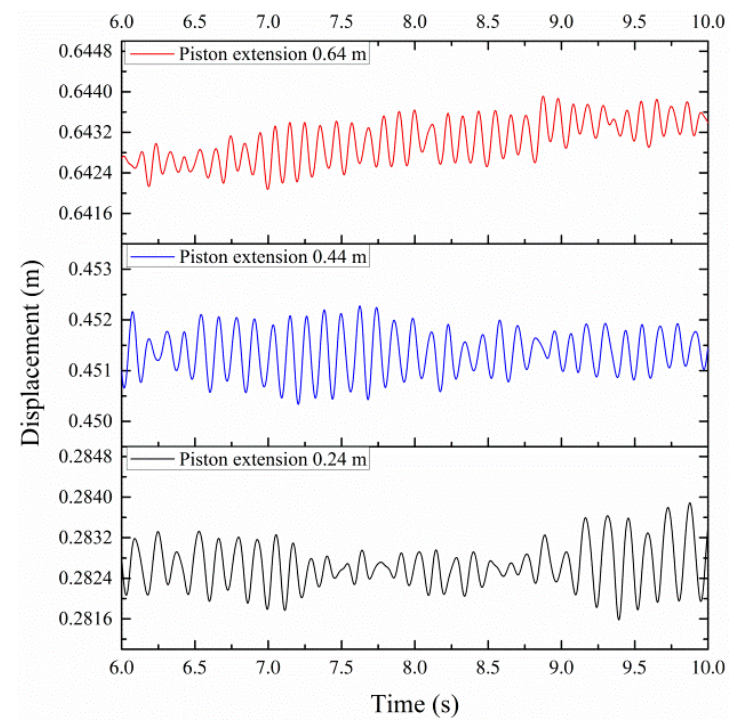

a) Piston displacements

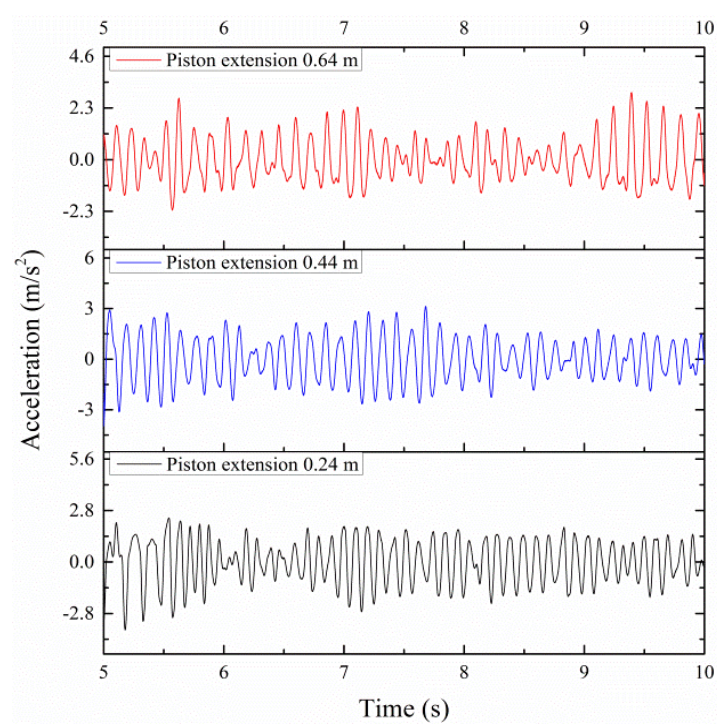

b) Piston accelerations

Figure 7: Dynamic responses of the hydraulic cylinder piston at different piston extrusions.

The load on the shearer drum varies with random fluctuations because of the interaction between the shearer drum and the coal. As a part of components for height adjustment in the shearer, the hydraulic cylinder easily suffers the impact from the load on the shearer drum, and it can be judged from the velocity and acceleration of the cylinder piston. Fig. 7 a shows that the piston does not work statically at $0.24,0.44$, and $0.64 \mathrm{~m}$ that are set in advance but fluctuates around $0.283,0.451$, and $0.643 \mathrm{~m}$ mainly because the cutting load on the shearer drum fluctuates during the working process, and the cylinder is always working under pressure. Therefore, deviation occurs on the cylinder's stable working positions. In addition, the velocity of the cylinder piston is not equal to zero, even if the shearer drum is adjusted to a certain height at the early stage, that is, the shearer drum is not kept at a fixed height, and it changes with the vibration of the cylinder piston in the entire coal cutting process.

Figs. 8 a and $8 \mathrm{~b}$ show the pressure on the rear and rod end of the cylinder when the shearer drum works at different heights, respectively. Fig. 8 a shows that the fluctuating range and the mean pressure on the rear end decrease gradually with time when the piston is at the extension of $0.64 \mathrm{~m}$. When the piston is at the extension of $0.44 \mathrm{~m}$, only the fluctuating range of the pressure decreases, and the mean of the pressure is substantially retained. When the piston is at the extension of $0.24 \mathrm{~m}$, the rear end pressure varies considerably, and the minimum pressure is zero. Therefore, when the shearer drum works at the height of $0.24 \mathrm{~m}$, the height adjustment cylinder suffers large, high fluctuations because of the increased force on the shearer drum along the piston working directions. Fig. 8 shows that the variation of drum working height influences the pressure on the rear and rod of the cylinder, but the effect on the pressure in the rear end of the cylinder is more substantial. The variation of drum working height also influences the pressure fluctuation frequency for two main reasons. On the one hand, the oil in the rear and rod end of the cylinder varies due to drum working height variation, which affects the resonant frequency. On the other hand, the evidently different force acting on the cylinder 
leads to the system dynamic characteristics, especially on the working process of CBEA-type counterbalance valve.

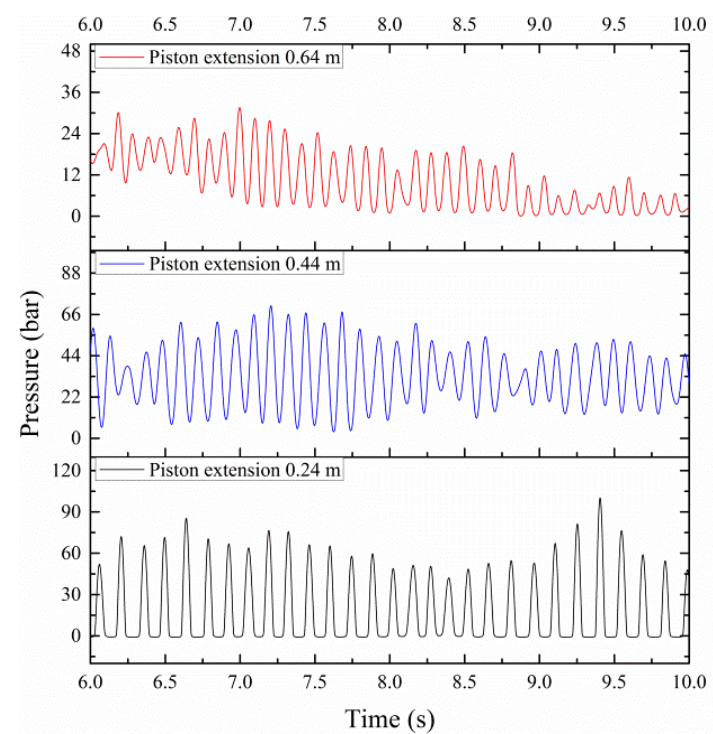

a) Rear end pressure

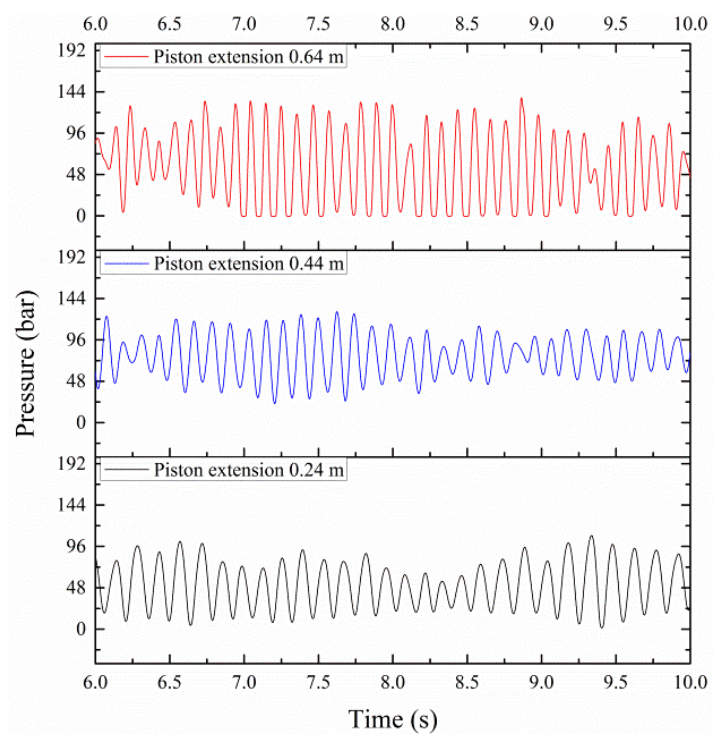

b) Rod end pressure

Figure 8: Pressures variation of the hydraulic cylinder at different piston extrusions.

\subsection{Statistics and analysis of simulation results}

In order to obtain more useful conclusions, some statistics, including mean and standard deviation, on the velocity and acceleration of motor gear and other parts in cutting system have been carried out, which are shown in Table I. According to the Table I, the difference of the velocity and acceleration when drum works at different cutting heights can be seen.

Table I a presents the meshing force and acceleration on the motor gear at different drum working heights. For the meshing force, the mean, minimum, and maximum increase with the drum working heights and the force increases are approximately linear with the variation of the drum working height. For the acceleration of the motor gear, the mean accelerations are similar and close to zero when the drum works at different heights. However, the absolute extremums of the motor gear acceleration increase with drum working heights, and the fluctuation of the motor gear acceleration enlarges evidently.

Table Ib shows the displacement and acceleration of the measurement point on the ranging arm at different drum working heights. The mean displacement on the measurement point is not equal to zero because the rocker housing used in this simulation is a rigid material. Slight displacements occur on the ranging arm, which mainly result from the small position change of the piston in the cylinder.

The mean and extreme meshing force and acceleration of the sun gear at different drum working heights are shown in Table Ic. The meshing force on the sun gear is slightly influenced by the drum working heights. In addition, the peak meshing force is far beyond the mean force, and the peak force is about 600 times larger than the mean force. Therefore, the peak meshing force is more easily influenced by the drum working heights and should be paid attention during the design process.

Table I d shows the velocity and acceleration of the piston under different cutting drum heights. When the shearer drum keeps working at a certain height, the velocity of the piston should keep static at a certain position because the piston does not need to work for height adjustment in this working situation. However, co-simulation revealed that the piston in the cylinder is in vibration, as shown in Table I d. Neither the mean nor the peak velocity is equal to zero. Therefore, the piston in cylinder is always in vibration rather than in a static condition. 
Sun, Jiang, Zeng, Gao, Zhang: Influence of Drum Cutting Height on Shearer Cutting Unit ...

Table I: Statistics of simulation results.

\begin{tabular}{|c|c|c|c|c|c|c|c|c|}
\hline No. & \multicolumn{2}{|c|}{ Content } & Drum & $\begin{array}{c}\text { Piston } \\
\text { extension }\end{array}$ & $\begin{array}{l}\text { Maximum } \\
\text { value }\end{array}$ & $\begin{array}{l}\text { Minimum } \\
\text { value }\end{array}$ & $\begin{array}{l}\text { Mean } \\
\text { value }\end{array}$ & $\begin{array}{l}\text { Standard } \\
\text { deviation }\end{array}$ \\
\hline \multirow{6}{*}{ a) } & \multirow{6}{*}{$\begin{array}{l}\text { Motor } \\
\text { gear }\end{array}$} & \multirow{3}{*}{$\begin{array}{l}\text { Meshing } \\
\text { force } \\
(\mathrm{N})\end{array}$} & 4311 & 0.64 & 127526.613 & 13893.667 & 57028.560 & 18061.327 \\
\hline & & & 3428 & 0.44 & 100760.530 & 10204.652 & 48511.666 & 15916.119 \\
\hline & & & 2607 & 0.24 & 81637.461 & 7765.616 & 38209.613 & 13509.027 \\
\hline & & \multirow{3}{*}{$\begin{array}{l}\text { Acceleration } \\
\left(\mathrm{m} / \mathrm{s}^{2}\right)\end{array}$} & 4311 & 0.64 & 1.546 & -2.365 & $7.38 \mathrm{E}-03$ & 0.762 \\
\hline & & & 3428 & 0.44 & 0.882 & -1.150 & $3.16 \mathrm{E}-03$ & 0.363 \\
\hline & & & 2607 & 0.24 & 0.005 & -0.00524 & $1.64 \mathrm{E}-05$ & 0.001 \\
\hline \multirow{6}{*}{ b) } & \multirow{6}{*}{$\begin{array}{l}\text { Point on } \\
\text { ranging } \\
\text { arm }\end{array}$} & \multirow{3}{*}{$\begin{array}{l}\text { Acceleration } \\
\left(\mathrm{m} / \mathrm{s}^{2}\right)\end{array}$} & 4311 & 0.64 & 6.778 & -9.388 & 0.005 & 3.713 \\
\hline & & & 3428 & 0.44 & 11.629 & -9.990 & -0.077 & 4.448 \\
\hline & & & 2607 & 0.24 & 11.628 & -6.811 & -0.516 & 3.675 \\
\hline & & \multirow{3}{*}{$\begin{array}{l}\text { Displacement } \\
\quad(\mathrm{m})\end{array}$} & 4311 & 0.64 & 0.137 & -0.132 & 5.97E-04 & 0.061 \\
\hline & & & 3428 & 0.44 & 0.183 & -0.194 & 4.16E-04 & 0.082 \\
\hline & & & 2607 & 0.24 & 0.199 & -0.190 & $6.13 \mathrm{E}-04$ & 0.075 \\
\hline \multirow{6}{*}{ c) } & \multirow{6}{*}{ Sun gear } & \multirow{3}{*}{$\begin{array}{l}\text { Meshing } \\
\text { force } \\
(\mathrm{N})\end{array}$} & 4311 & 0.64 & 45687.555 & -55979.73 & 68.845 & 22748.813 \\
\hline & & & 3428 & 0.44 & 48679.674 & -50821.65 & -350.544 & 22836.226 \\
\hline & & & 2607 & 0.24 & 48075.113 & -47278.10 & -489.833 & 22791.294 \\
\hline & & \multirow{3}{*}{$\begin{array}{l}\text { Acceleration } \\
\left(\mathrm{m} / \mathrm{s}^{2}\right)\end{array}$} & 4311 & 0.64 & 4.988 & -6.934 & -0.008 & 2.740 \\
\hline & & & 3428 & 0.44 & 4.186 & -3.623 & 0.019 & 1.608 \\
\hline & & & 2607 & 0.24 & 1.200 & -0.726 & 0.006 & 0.384 \\
\hline \multirow{6}{*}{ d) } & \multirow{6}{*}{$\begin{array}{c}\text { Hydraulic } \\
\text { cylinder } \\
\text { piston }\end{array}$} & \multirow{3}{*}{$\begin{array}{l}\text { Acceleration } \\
\left(\mathrm{m} / \mathrm{s}^{2}\right)\end{array}$} & 4311 & 0.64 & 2.399 & -3.695 & $1.77 \mathrm{E}-03$ & 0.974 \\
\hline & & & 3428 & 0.44 & 3.135 & -3.138 & $1.55 \mathrm{E}-02$ & 1.285 \\
\hline & & & 2607 & 0.24 & 2.994 & -2.254 & $4.22 \mathrm{E}-03$ & 1.186 \\
\hline & & \multirow{3}{*}{$\begin{array}{l}\text { Velocity } \\
\left(\mathrm{m} / \mathrm{s}^{2}\right)\end{array}$} & 4311 & 0.64 & 0.040 & -0.039 & $1.74 \mathrm{E}-04$ & 0.018 \\
\hline & & & 3428 & 0.44 & 0.050 & -0.053 & $1.13 \mathrm{E}-04$ & 0.022 \\
\hline & & & 2607 & 0.24 & 0.052 & -0.049 & $1.60 \mathrm{E}-04$ & 0.019 \\
\hline \multirow{6}{*}{ e) } & \multirow{6}{*}{$\begin{array}{l}\text { Pressure } \\
\text { in } \\
\text { hydraulic } \\
\text { cylinder }\end{array}$} & \multirow{3}{*}{$\begin{array}{l}\text { Pressure } \\
\text { (bar) }\end{array}$} & 4311 & 0.64 & 136.985 & -0.755 & 55.244 & 40.698 \\
\hline & & & 3428 & 0.44 & 128.752 & 22.117 & 77.272 & 23.863 \\
\hline & & & 2607 & 0.24 & 108.673 & 1.493 & 51.246 & 26.308 \\
\hline & & \multirow{3}{*}{$\begin{array}{l}\text { Rear pressure } \\
\text { (bar) }\end{array}$} & 4311 & 0.64 & 31.547 & 0.072 & 10.344 & 7.943 \\
\hline & & & 3428 & 0.44 & 70.611 & 3.510 & 33.135 & 15.368 \\
\hline & & & 2607 & 0.24 & 100.153 & -0.901 & 17.649 & 24.497 \\
\hline
\end{tabular}

For the hydraulic cylinder, the pressure on the rod end is larger than that on the rear end, as verified again in Table I e. The pressure on the rear and rod end of the cylinder reaches the maximum when the shearer works at the height of $3428 \mathrm{~m}$. The fluctuation of pressure on the rear end of the cylinder shrinks with the increase of drum positions, whereas the pressure on the rod end of the cylinder is slightly influenced by the positions of the shearer drum. Thus, the pressure is more stable for the variation in the rear end of the cylinder when the shearer drum is on the ascend or descend process. 


\section{CONCLUSIONS}

The study discusses the hydromechatronical co-simulation model of the cutting department of the mining machine using ADAMS, AMESim, and MATLAB software. Using the proposed model, the dynamic responses of shearer are accessible. According to the analysis of the results, the following can be concluded:

(1) The peak meshing force on the gear, whether sun gear or motor gear, is greatly larger than the mean. The phenomenon is much more evident on the sun gear, and the peak meshing force on the sun gear is several dozen times higher than the mean meshing force. In addition, the meshing force on the motor gear, whether the mean force or maximum force, is clearly larger than that on the sun gear. Compared with the sun gear, the motor gear tends to suffer damage more easily. Therefore, considering the influence of drum working height during motor gear design process is important.

(2) The vibration of the ranging arm is not influenced directly by drum cutting height but is related to the vibration of the piston rod in the hydraulic cylinder. With the increase of drum working height, the mean pressure on the rear and rod end of the cylinder decreases first and then increases. Therefore, the fixed position of the hydraulic cylinder for height adjustment should be carefully paid attention. Pressure variation and piston jitter cause damage on the hydraulic components, especially the seal elements. Therefore, accumulator or dynamic pressure feedback device can be considered during hydraulic adjustment system design to reduce the pressure fluctuation in the system.

The hydromechatronical co-simulation model of transmission and hydraulic system was established and the dynamic responses of some important components of shearer were obtained. However, the vibration of the ranging arm cannot be fed back to the shearer drum using the method in this study, and it might lead to several deviations between the results obtained in this part and those from real working conditions. Hence, a co-simulation model that conforms to real working conditions better should be found to obtain more accurate results.

\section{ACKNOWLEDGEMENT}

This work was supported in part by the Natural Science Foundation of China (Grant No. 51704178); Project of Shandong Province Higher Educational Young Innovative Talent Introduction and Cultivation Team (Performance enhancement of deep coal mining equipment); the Postdoctoral Science Foundation of China (Grant No. 2019M662403).

\section{REFERENCES}

[1] Reid, A. W.; McAree, P. R.; Meehan, P. A.; Gurgenci, H. (2014). Longwall shearer cutting force estimation, Journal of Dynamic Systems, Measurement, and Control, Vol. 136, No. 3, Paper 031008, 9 pages, doi: $10.1115 / 1.4026326$

[2] Fedai, Y.; Kahraman, F.; Kirli, A. H.; Basar, G. (2018). Optimization of machining parameters in face milling using multi-objective Taguchi technique, Technical Journal, Vol. 12, No. 2, 104-108, doi:10.31803/tg-20180201125123

[3] Mężyk, A.; Klein, W.; Fice, M.; Pawlak, M.; Basiura, K. (2016). Mechatronic model of continuous miner cutting drum driveline, Mechatronics, Vol. 37, 12-20, doi:10.1016/ j.mechatronics.2015.11.004

[4] Gao, K.; Du, C.; Liu, S.; Fu, L. (2014). Analysis on significance of the factors influencing shearer drum cutting performance, International Journal of Oil, Gas and Coal Technology, Vol. 7, No. 4, 386-398, doi:10.1504/IJOGCT.2014.062170

[5] Che, D.; Zhu, W.-L.; Ehmann, K. F. (2016). Chipping and crushing mechanisms in orthogonal rock cutting, International Journal of Mechanical Sciences, Vol. 119, 224-236, doi: $\underline{10.1016 / j . i j m e c s c i .2016 .10 .020}$ 
[6] Liu, X.; Liu, S.; Cui, X.; Tang, P. (2014). Interference model of conical pick in cutting process, Journal of Vibroengineering, Vol. 16, No. 1, 103-115

[7] Akhshik, S.; Rajabi, M. (2018). CFD-DEM modeling of cuttings transport in underbalanced drilling considering aerated mud effects and downhole conditions, Journal of Petroleum Science and Engineering, Vol. 160, 229-246, doi:10.1016/j.petrol.2017.05.012

[8] Moon, T.; Oh, J. (2012). A study of optimal rock-cutting conditions for hard rock TBM using the discrete element method, Rock Mechanics and Rock Engineering, Vol. 45, No. 5, 837-849, doi:10.1007/s00603-011-0180-3

[9] Cruz Gonzalez, G. C.; Gutierrez, S. S.; Tijerina, J. J. T.; Romero Llerenas, R.; Jamilloux, A.; Gamez Cuatzin, H.; Gonzalez Garcia, P. (2018). Finite element evaluation for adhesive joints dissimilar material (steel - aluminum), Dyna, Vol. 93, No. 4, 404-410, doi:10.6036/8619

[10] Blecich, P.; Senčić, T.; Wolf, I.; Bonefačić, I. (2018). Numerical investigation of heat and mass transfer inside a wet cooling tower, Technical Journal, Vol. 12, No. 3, 131-138, doi:10.31803/tg20171017145907

[11] Menezes, P. L.; Lovell, M. R.; Avdeev, I. V.; Lin, J.-S.; Higs III, C. F. (2014). Studies on the formation of discontinuous chips during rock cutting using an explicit finite element model, The International Journal of Advanced Manufacturing Technology, Vol. 70, No. 1-4, 635-648, doi:10.1007/s00170-013-5309-y

[12] Wan, L.; Jiang, K.; Gao, K.; Zeng, Q.; Zhang, X. (2019). Research of response difference on coal cutting load under different cutting parameters, Strojniski vestnik - Journal of Mechanical Engineering, Vol. 65, No. 7-8, 420-429, doi:10.5545/sv-jme.2018.5940

[13] Chen, J.; Li, W.; Sheng, L.; Jiang, S.; Li, M. (2020). Study on reliability of shearer permanent magnet semi-direct drive gear transmission system, International Journal of Fatigue, Vol. 132, Paper 105387, 22 pages, doi:10.1016/j.ijfatigue.2019.105387

[14] Sheng, L.; Li, W.; Jiang, S.; Chen, J.; Liu, A. (2019). Nonlinear torsional vibration analysis of motor rotor system in shearer semi-direct drive cutting unit under electromagnetic and load excitation, Nonlinear Dynamics, Vol. 96, No. 2, 1677-1691, doi:10.1007/s11071-019-04878-x

[15] Hoseinie, S. H.; Ataei, M.; Khalokakaie, R.; Ghodrati, B.; Kumar, U. (2012). Reliability analysis of drum shearer machine at mechanized longwall mines, Journal of Quality in Maintenance Engineering, Vol. 18, No. 1, 98-119, doi:10.1108/13552511211226210

[16] Hoseinie, S. H.; Ghodrati, B.; Kumar, U. (2014). Cost-effective maintenance scheduling of cutting arms of drum shearer machine, International Journal of Mining, Reclamation and Environment, Vol. 28, No. 5, 297-310, doi:10.1080/17480930.2014.950453

[17] Yang, D.-L.; Li, J.-P.; Wang, Y.-X.; Jiang, H.-X. (2018). Analysis on vertical steering vibration of drum shearer cutting part, Journal of Central South University, Vol. 25, No. 11, 2722-2732, doi:10.1007/s11771-018-3949-7

[18] Wang, H.; Sun, D.; Qin, D. (2016). A new continuously variable transmission system applied to transmission system of the roadheader's cutting unit, Proceedings of the Institution of Mechanical Engineers, Part C: Journal of Mechanical Engineering Science, Vol. 231, No. 19, 3590-3600, doi:10.1177/0954406216649404

[19] Liu, C.; Qin, D.; Liao, Y. (2015). Electromechanical dynamic analysis for the drum driving system of the long-wall shearer, Advances in Mechanical Engineering, Vol. 7, No. 10, Paper 1687814015598694, 14 pages, doi:10.1177/1687814015612031

[20] Barbagallo, R.; Sequenzia, G.; Oliveri, S. M.; Cammarata, A. (2016). Dynamics of a highperformance motorcycle by an advanced multibody/control co-simulation, Proceedings of the Institution of Mechanical Engineers, Part K: Journal of Multi-body Dynamics, Vol. 230, No. 2, 207-221, doi: $10.1177 / 1464419315602825$

[21] Meng, Z. S.; Zhang, S.; Xie, Y. Y.; Zeng, Q. L. (2020). Attitude adjustment of backfilling support based on mechanical-hydraulic co-simulation, International Journal of Simulation Modelling, Vol. 19, No. 3, 399-409, doi:10.2507/IJSIMM19-3-520

[22] Ren, W. J.; Wang, L.; Mao, Q. H.; Jiang, S. B.; Huang, S. (2020). Coupling properties of chain drive system under various and eccentric loads, International Journal of Simulation Modelling, Vol. 19, No. 4, 643-654, doi:10.2507/IJSIMM19-4-535 
[23] Zeng, Q.; Gao, K.; Zhang, H.; Jiang, S.; Jiang, K. (2017). Vibration analysis of shearer cutting system using mechanical hydraulic collaboration simulation, Proceedings of the Institution of Mechanical Engineers, Part K: Journal of Multi-body Dynamics, Vol. 231, No. 4, 708-725, doi: $10.1177 / 1464419317705986$

[24] Gao, K.; Meng, Z.; Jiang, K.; Zhang, H.; Zeng, Q. (2020). Shearer height adjustment based on mechanical-electrical-hydraulic cosimulation, IEEE Access, Vol. 8, 222064-222076, doi:10.1109/ACCESS.2020.3043516

[25] Wang, Y.; Bai, F.; Li, S.; Yang, Y. (2020). Modelling and dynamic behavior of a vibratory roller for soil compacting based on lumped-parameter method, Dyna, Vol. 95, No. 6, 615-621, doi: $\underline{10.6036 / 9867}$ 